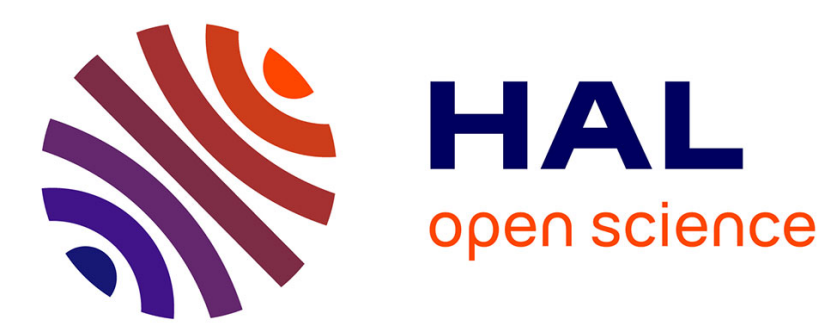

\title{
A critical look at EL2 models
}

\author{
J.C. Bourgoin, M. Lannoo
}

\section{- To cite this version:}

J.C. Bourgoin, M. Lannoo. A critical look at EL2 models. Revue de Physique Appliquée, 1988, 23

(5), pp.863-869. 10.1051/rphysap:01988002305086300 . jpa-00245889

\section{HAL Id: jpa-00245889 https://hal.science/jpa-00245889}

Submitted on 1 Jan 1988

HAL is a multi-disciplinary open access archive for the deposit and dissemination of scientific research documents, whether they are published or not. The documents may come from teaching and research institutions in France or abroad, or from public or private research centers.
L'archive ouverte pluridisciplinaire HAL, est destinée au dépôt et à la diffusion de documents scientifiques de niveau recherche, publiés ou non, émanant des établissements d'enseignement et de recherche français ou étrangers, des laboratoires publics ou privés. 


\title{
A critical look at EL2 models
}

\author{
J. C. Bourgoin $\left({ }^{1}\right)$ and M. Lannoo $\left({ }^{2}\right)$
}

( ${ }^{1}$ ) Groupe de Physique des Solides de l'Ecole Normale Supérieure, Université Paris VII, Tour 23, 2 place Jussieu, 75251 Paris Cedex 05, France

$\left({ }^{2}\right)$ Laboratoire de Physique des Solides, Institut Supérieur d'Électronique du Nord, 41 boulevard Vauban, 59046 Lille Cedex, France

(Reçu le 15 juillet 1987, accepté le 2 novembre 1987)

\begin{abstract}
Résumé. - Nous faisons une discussion critique des observations expérimentales faites sur EL2, ce qui nous amène à conclure que la configuration la plus probable de ce défaut est la paire As antisite-As interstitiel.

Abstract. - A critical discussion of the experimental observations made on the EL2 defect in GaAs is made which allows us to conclude that the most probable configuration of this defect is the As antisite-As interstitial pair.
\end{abstract}

\section{Introduction.}

Most of the studies devoted to the so-called EL2 [1] native defect in GaAs have been primarily focused on the determination of its electronic properties leading to phenomenological descriptions in terms of configuration coordinate diagrams. However, there has been recently some progress made concerning the microscopic identification of this defect. Unfortunately, the results are not yet complete since they concern mainly the stable ground state and a considerable uncertainty remains concerning the metastable configuration.

Numerous models have been proposed, that often include only a part of the experimental observations available at the time they are published, which are claimed to represent the defect. The reason for such numerous proposals is that the nature and precise atomic configuration of this defect cannot be readily obtained: none of the techniques available for the characterization of defects in semiconductors is able to give a complete answer. Each technique provides a piece of information and the gathering of all pieces is perhaps not yet sufficient to provide the exact picture.

The missing pieces are of atomic nature rather than the electronic properties which are a consequence of the nature of the defect. This is the reason why the study of the atomic behaviour of the defect, combined with its electronic characteristics, has allowed to make recently some progress towards its identification [2,3].

The aim of this paper is to discuss the various existing models in the light of the most reliable experimental data available. From this we shall derive a configuration coordinate diagram which describes best the electronic properties of the defect and extract the nature of the most probable atoms which compose it. Then we shall examine the most likely mechanisms which can account for its metastability. We shall see that practically none of the proposed model are capable of giving a full account of all the known data and we shall try to give some suggestions that might help improving this situation.

In a first part we give a brief review of what we believe to be the crucial properties of EL2 that any serious model should explain. From this we draw some preliminary conclusions concerning its possible atomic constituents. In a second part we give some account of the models that have been proposed and analyse their possible shortcomings at least with regard to their description of the stable state. We then summarize the available theoretical calculations and confront them to the experimental data. We end up by a discussion confirming the soundness of the identification of the defect as a $\mathrm{As}_{\mathrm{Ga}}-\mathrm{As}_{\mathrm{i}}$ complex and present some possibilities that could explain the origin of the metastable state. 


\section{Physical properties of EL2.}

We list here the well established features of EL2 which will serve as the basic elements for our discussion.

First, EL2 is a donor [4]. It is characterized by a midgap donor level $E_{1}$ (which does not necessarily correspond to the $0 \rightarrow+$ transition) whose location has been obtained from DLTS experiments [5] to be at $0.72 \pm 0.02 \mathrm{eV}$ below the conduction band. Recently, a double donor state has also been detected at $E_{2}=0.54 \mathrm{eV}$ above the valence band edge and ascribed to EL2 [6].

The temperature dependence of the electron capture cross-section $\sigma_{\mathrm{n}}$ on the $E_{1}$ level gives an idea of the Franck-Condon shift [7] $S \hbar \omega=140 \pm 10 \mathrm{meV}$, confirmed by the more precise value deduced from the electric field dependence of the emission rate [8]. Such a value indicates a moderate, but non negligible, electron-phonon interaction of the stable state of EL2. This level picture has been completed by a detailed analysis of the photoionization cross-sections $\sigma_{\mathrm{n}}^{0}$ and $\sigma_{\mathrm{p}}^{0}$ leading [9] to a value of $S \hbar \omega$ of the same order magnitude as the above one. The combined electrical and optical ionization information allow to draw the configuration coordinate diagram of figure 1 which agrees with the observation of associated luminescence bands $[10,11]$.

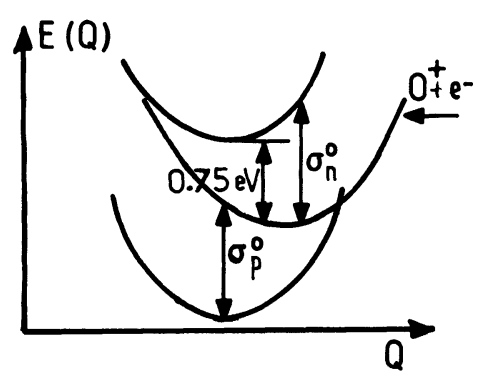

Fig. 1. - Lattice relaxation configuration diagram of EL2 as deduced from thermal and photoionization data.

The most characteristic feature of EL2 is its quenching behaviour which is observed through various techniques. For instance, in photocapacitance studies, the sample is cooled in the dark at $T<140 \mathrm{~K}$ under conditions where EL2 is filled (the so-called $O$ state). It is then illuminated under reverse bias ; for $h \nu$ between 0.9 and $1.35 \mathrm{eV}$ the photocapacitance first increases rapidly and then decreases to a value of the order of the original one [7]. This indicates a transition from the stable state $\mathrm{O}$ to a new state (usually called $\mathrm{O}^{*}$ ), $\mathrm{O}$ and $\mathrm{O}^{*}$ having the same charge state. Indeed, since this process can occur in the space charge region of a junction, a transfer of charge from EL2 to another nearby defect should be ruled out. The $\mathrm{O}^{*}$ state is metastable since the stable state can be regenerated [12] either thermally at a rate $r$ :

$$
r\left(S^{-1}\right) \simeq 10^{11} \exp -\frac{0.3}{k T}(\mathrm{eV})
$$

or under electron injection conditions with a rate proportional to the density of the injected electrons. The cross-section $\sigma^{*}(h \nu)$ for the optically induced transition from $\mathrm{O} \rightarrow \mathrm{O}^{*}$ is peaked at $1.1 \mathrm{eV}$, energy at which $\sigma_{\mathrm{n}}^{0} \sim \sigma_{\mathrm{p}}^{0} \sim 10 \sigma^{*}$ [7] (of the order of $10^{-16} \mathrm{~cm}^{-2}$ ). It has also been argued from a comparison between the optical absorption and the photoionization spectrum that such optical transition is related to an intra-centre optical absorption band [13] similar to $\sigma^{*}(h \nu)$ and whose zero-phonon line corresponds to an $A_{1} \rightarrow T_{2}$ transition characteristic of an undistorted $T_{d}$ centre. However, a recent high resolution study [14] of this absorption band shows that it could have a fine structure, different from the one claimed in reference [13], that might be typical of a defect pair in weak interaction.

In an early work [15] it was demonstrated that EL2 gives rise to an EPR spectrum characteristic of the arsenic antisite $\mathrm{As}_{\mathrm{Ga}}^{+}$. Two levels seem to be associated with this defect which are, within experimental uncertainty, the ones $\left(E_{1}\right.$ and $\left.E_{2}\right)$ associated with the EL2 electrical levels. Furthermore, photoEPR experiments show clear similarities with the optical cross-sections of EL2. This, associated with the apparent $T_{\mathrm{d}}$ symmetry of this defect has led several authors $[13,15]$ to postulate that EL2 is the isolated antisite. However, much progress has been achieved recently $[2,3]$ proving that EL2 must be a complex involving the antisite, which one can write

$$
\mathrm{EL} 2=\mathrm{As}_{\mathrm{Ga}}+X
$$

This was proved from independent arguments. First combined DLTS and EPR measurements have allowed to show the following points : i) there are two types of EPR antisite defects in electron irradiated semi-insulating material, a stable one and a quenchable one which exists in the material prior to irradiation (the fact that these two spectra are practically identical shows that $X$ must be distant enough from $\mathrm{As}_{\mathrm{Ga}}$ in the paramagnetic state for the EPR spectrum to remain the same) ; ii) after thermal annealing at $850^{\circ} \mathrm{C}$ (in an unirradiated material) the metastable antisite transforms into a stable one, indicating a probable dissociation of the complex ; iii) when the thermal treatment is followed by a quench it is argued that the regeneration of the metastable entity occurs around $130^{\circ} \mathrm{C}$, indicating reformation of the complex through the mobility of $X$ since the antisite is stable well above this temperature; iv) the thermal behaviour of $X$ strongly suggests that it should be identified with the arsenic 
interstitial $\mathrm{As}_{\mathrm{i}}$, proposed to be at two interatomic distances from $\mathrm{As}_{\mathrm{Ga}}$ in the stable state $[2,3]$.

The second clear piece of evidence for EL2 being such a complex comes from optically detected EPR and ENDOR measurements [16]. Here the conclusions are the following : i) the paramagnetic state of EL2 is a complex consistent with $\mathrm{As}_{\mathrm{Ga}}^{+}$and $X=\mathrm{As}_{\mathrm{i}}^{+}$ or $\mathrm{As}_{\mathrm{i}}^{-}$at two interatomic distances along an antibonding (111) direction ; the $\mathrm{As}_{\mathrm{i}}^{0}$ possibility is excluded since it is a paramagnetic defect whose interaction with $\mathrm{As}_{\mathrm{Ga}}^{+}$would be seen in the spectra ; ii) in p-type doped material the optical excitation allows to detect the two levels $E_{1}$ and $E_{2}$ and it is only when the $E_{1}$ level is filled that the $1.1 \mathrm{eV}$ absorption transforms the stable $O$ state into the metastable $\mathrm{O}^{*}$ state.

The main conclusion that can be drawn thus concerns the stable paramagnetic state as being the $\mathrm{As}_{\mathrm{Ga}}^{+}-\mathrm{As}_{\mathrm{i}}^{ \pm}$complex. However, since the $E_{1}$ level is a donor state, one should conclude that the stable state of EL2 must be the $2+$ and + states which correspond to the pair $\mathrm{As}_{\mathrm{Ga}}^{+}-\mathrm{As}_{\mathrm{i}}^{+}$and $\mathrm{As}_{\mathrm{Ga}}^{0}-\mathrm{As}_{\mathrm{i}}^{+}$, respectively. In the $2+$ state configuration there is electrostatic repulsion between the two elements of the pair which might explain why the stable situation corresponds to an $\mathrm{As}_{\mathrm{Ga}}^{+}-\mathrm{As}_{\mathrm{i}}^{+}$with a separation of two interatomic distances [3]. We have not much information on the configuration of the other charge states of the pair, i.e. EL2 (+) an EL2 $(3+)$ except that the Franck-Condon shift of the $(+, 2+)$ transition (i.e. corresponding to the level $E_{1}$ ) is of order $130 \mathrm{meV}$ with a phonon energy of $\sim 20 \mathrm{meV}$.

\section{Phenomenological models for the optical transition to the metastable state.}

We investigate here the different models that have been proposed to account for the transition from the $\mathrm{O}$ to the $\mathrm{O}^{*}$ states and try to discuss them in the light of what has been learnt for the ground state.

The most simple model, originally proposed by Vincent et al. [7], assumes that the optical transition around $1.1 \mathrm{eV}$ is an internal one that occurs when the midgap level $E_{1}$ is filled. Then the optical transitions occur with rates $\sigma_{\mathrm{n}}^{0} \phi, \sigma_{\mathrm{p}}^{0} \phi$ ( $\phi$ being the photon flux) for photoionization and $\sigma^{*} \phi$ for optical transition to the metastable state. Calling $N$ and $N^{*}$ the concentrations of the defects in the $\mathrm{O}$ and $\mathrm{O}^{*}$ states, and $N_{\mathrm{T}}$ their total concentration, one gets the rate equations

$\frac{\mathrm{d} N}{\mathrm{~d} t}=-\sigma_{\mathrm{n}}^{0} \phi N+\sigma_{\mathrm{p}}^{0} \phi\left(N_{\mathrm{T}}-N-N^{*}\right)-\sigma^{*} \phi N$

$\frac{\mathrm{d} N *}{\mathrm{~d} t}=\sigma^{*} \phi N$

at low temperature in which case thermal regeneration is negligible. If, as is the case experimentally, we take $\sigma^{*}$ to be much smaller than $\sigma_{\mathrm{n}}^{0}, \sigma_{\mathrm{p}}^{0}$, then we can analyse the two transients separately. The shortest one is obtained from the first equation with $N^{*}$ constant and $\sigma^{*}=0$ leading to a time constant equal to $\left(\sigma_{\mathrm{n}}^{0}+\sigma_{\mathrm{p}}^{0}\right) \phi$, after which $N$ reaches a saturation value equal to $\left[\sigma_{\mathrm{p}}^{0} /\left(\sigma_{\mathrm{n}}^{0}+\sigma_{\mathrm{p}}^{0}\right)\right]$ $\left(N_{\mathrm{t}}-N^{*}\right)$. The second transient is obtained by inserting this value of $N$ in the second equation which leads to a time constant $\sigma^{*} \sigma_{\mathrm{p}}^{0}\left(\sigma_{\mathrm{n}}^{0}+\sigma_{\mathrm{p}}^{0}\right)^{-1}$. This model naturally explains the shape of the capacitance transient. It leads to the configuration coordinate diagram of figure 1 which allows a direct interpretation of the thermal regeneration rate but not of the mechanism of regeneration under electron injection. The main characteristic of this model is that the $\mathrm{O} \rightarrow \mathrm{O}^{*}$ transition is an internal one where the defect keeps a constant charge state.

The second model, of different nature, is due to Levinson [17]. There, the $O$ state is characterized by two levels, a shallow donor one, $D$, and the midgap level, $C$, which can have different charge states. In the stable $O$ state, the system is assumed to be a close pair of charged defects $\left(\mathrm{C}^{-} \mathrm{D}^{+}\right)^{0}$, i.e. the neutral state of the pair. In this state the two defects are bound by electrostatic attraction. When a first electron is lost by the pair, from a level $O_{1}$, it gives rise to $\left(\mathrm{C}^{0} \mathrm{D}^{+}\right)^{+}$still stable in the original configuration. However, in the photocapacitance quenching experiment, a second electron is ionized, from a level $O_{2}$, at a rate $\sigma_{\mathrm{p}}^{0 *} \phi$. It is from this state that the thermal regeneration occurs at high enough temperature. Regeneration under electron injection is explained by the capture of an electron by the $\left(\mathrm{O}^{*}\right)^{+}$system transforming it into the neutral $\left(\mathrm{O}^{*}\right)^{0}$, i.e. the $\left(\mathrm{C}^{-} \mathrm{D}^{+}\right)^{0}$ configuration, which, due to Coulomb attraction, spontaneously comes back to the orignal $\mathrm{O}$ configuration. For such a system, assuming that $\mathrm{O}^{2+}$ transforms instantaneously to $\left(\mathrm{O}^{*}\right)^{2+}$, one gets the kinetic equations :

$$
\begin{aligned}
& \frac{\mathrm{d} N}{\mathrm{~d} t}=-\sigma_{\mathrm{n}}^{0} \phi N \\
& \frac{\mathrm{d} N^{*}}{\mathrm{~d} t}=\sigma_{\mathrm{p}}^{0^{*}} \phi\left(N_{\mathrm{T}}-N-N^{*}\right)
\end{aligned}
$$

where $N$ and $N^{*}$ are the concentrations of defects in the $\mathrm{O}^{+}$and $\left(\mathrm{O}^{*}\right)^{+}$charge states. Again simple solutions are found and the time constant for electron ionization is $\sigma_{\mathrm{n}}^{0}$ while the time constant for quenching is $\sigma_{\mathrm{p}}^{0 *} \phi$.

In principle the two models provide an explanation of photoquenching and the second one seems superior in explaining regeneration under electron injection. However, one basic weakness of Levinson's model is that the $\mathrm{O} \rightarrow \mathrm{O}^{*}$ transformation occurs as soon as the photoionization takes place from the $\mathrm{O}_{2}$ level, i.e. the EL2 midgap level $E_{1}$ at $E_{\mathrm{c}}-0.75 \mathrm{eV}$. This is not observed since the photoquenching cross-section $\sigma^{*}(h \nu)$ is non-zero 
only for $h \nu>0.9 \mathrm{eV}$ excluding that the $\mathrm{O} \rightarrow \mathrm{O}^{*}$ transformation could be induced by photoionization alone. To our opinion this rules out Levinson's model. However, this electrostatic view of metastability is attractive and has led Bardeleben et al. [3] to propose another model, based on the same physical considerations, but including more recent information. They start from the stable $\mathrm{O}$ configuration of EL2 as being the second nearest neighbour $\left(A s_{G a}-A s_{i}\right)$ pair. As discussed above, the EPR state is likely to correspond to the $\left(\mathrm{As}_{\mathrm{Ga}}^{+}-\mathrm{As}_{\mathrm{i}}^{2+}\right)$ situation. When the midgap level $E_{1}$ is filled, they assume that the pair changes to $\mathrm{As}_{\mathrm{Ga}}^{0}-\mathrm{As}_{\mathrm{i}}^{+}$still stable in the $\mathrm{O}$ configuration. Their explanation of photoquenching is that under light illumination a fraction of the EL2 population can be transformed into $\mathrm{As}_{\mathrm{Ga}}^{-} \mathrm{As}_{\mathrm{i}}^{+}$, by the transfer of one electron, through internal excitation, from $\mathrm{As}_{\mathrm{i}}$ to $\mathrm{As}_{\mathrm{Ga}}$ [18]. Then, due to Coulomb attraction, this $\mathrm{O}$ configuration transforms into the $\mathrm{O}^{*}$ one, with $\mathrm{As}_{\mathrm{i}}$ is first neighbour position of $\mathrm{As}_{\mathrm{Ga}}$.

There have been other models proposed. However, these models can be ruled out quite simply because they do not take into account all the available information. The most recent one is due to Wager and Van Vechten [19] who developed a model, based on a complex involving $\mathrm{As}_{\mathrm{Ga}}$ and two vacancies, originally proposed by Zou [20]. Not only such a model could hardly explain the ENDOR observations but it is also based on the existence of the divacancy detected by positron annihilation [21] which is known to anneal, by the same technique, at a temperature $\left(\sim 450^{\circ} \mathrm{C}\right)$ where EL2 is still stable. (These observations obtained through positron annihilation data are important since they rule out all models involving vacancy related defects). Moreover, the photoquenching is assumed to be due to an internal excitation of $\mathrm{V}_{\mathrm{Ga}}^{-}$in the complex $\mathrm{V}_{\mathrm{As}}^{+} \mathrm{V}_{\mathrm{Ga}}^{-} \mathrm{As}_{\mathrm{Ga}}^{+}$, which is obviously incorrect since this state corresponds to paramagnetic $\mathrm{As}_{\mathrm{Ga}}$ and we have seen that, experimentally, the quenching does not occur in this state but in the diamagnetic state corresponding to filled $E_{1}$ level. A final argument against this model is that the $\mathrm{O} \rightarrow \mathrm{O} *$ transformation involves a transition configuration needing the ionization and retrapping of three electrons, which is obviously hard to imagine.

As to the model of Figielski [22], a complex of two $\mathrm{As}_{\mathrm{Ga}}$ with an $\mathrm{As}_{\mathrm{i}}$, it is in contradiction with the EPR observation of a spin $1 / 2$ centre associated with the defect.

The main conclusion of this section is therefore that the $\mathrm{As}_{\mathrm{Ga}}-\mathrm{As}_{\mathrm{i}}$ complex should be preferred and that, among the two distinct types of models, i.e. the configuration coordinate model with internal quenching excitation and the electrostatic model where the $\mathrm{O} \rightarrow \mathrm{O}^{*}$ transformation is induced by photoionization, the first one seems more founded. However, the electrostatic model has several interesting features that we should keep in mind. A recent work [23] has shown that the photocapacitance cross-section $\sigma^{*}(h \nu)$ is indeed closely related to the corresponding optical absorption at $1.2 \mathrm{eV}$ with the same zero phonon line and similar phonon structure. However, a full analysis of the data tends to indicate that one should consider several energy branches for the configuration coordinate diagram in the photoexcited state.

\section{Theoretical considerations.}

The proposal that EL2 might be the isolated $\mathrm{As}_{\mathrm{Ga}}$ antisite has stimulated many theoretical calculations of this defect in the undistorted $T_{d}$ site. As usual, such calculations are either based on local density theory or on empirical tight binding approaches. The relative merits of these two techniques are discussed in reference [24] and we shall not comment on these aspects here.

The level structure of the antisite can be understood easily in a molecular picture [25]. When replacing a $\mathrm{Ga}$ atom, As tends to reform the same covalent bonds. However, it is more electronegative and this tends to stabilize an $A_{1}$ combination of antibonding states in the gap, the corresponding $T_{2}$ combination being a resonant state in the lower part of the conduction band. In the neutral charge state the two excess electrons of As occupy the $A_{1}$ level giving rise to a diamagnetic centre. In the singly ionized state $\mathrm{As}_{\mathrm{Ga}}^{+}$becomes EPR active. The theoretical predictions mostly concern the position of the $\varepsilon(0,+)$ and $\varepsilon(+, 2+)$ levels in the gap neglecting possible contributions due to atomic relaxation. There is considerable scatter in the results, with $[26,27]$

$$
-0.75 \mathrm{eV}<\varepsilon(0,+)-E_{\mathrm{c}}<-0.02 \mathrm{eV}
$$

and a remarkably constant effective Coulomb term $U=\varepsilon(0,+)-\varepsilon(+, 2+)$ of about $0.25 \mathrm{eV}$ [28]. Another important result is that the $A_{1}-T_{2}$ splitting (where $T_{2}$ is the resonant conduction band state) is of order 0.9 to $1 \mathrm{eV}$.

The conclusion that EL2 is the isolated $\mathrm{As}_{\mathrm{Ga}}$ was based on these results and on the fact that the splitting of the zerophonon line of the intracentre optical transition under uniaxial stress is consistent with an $A_{1} \rightarrow T_{2}$ transition [13]. In this picture, the two levels $\varepsilon(0,+)$ and $\varepsilon(+, 2+)$ are identified with $E_{1}$ and $E_{2}$. Unconvincing reasons for explaining the instability of the $T_{2}$ photoexcited state have been presented; however, for the reasons discussed above, such an identification has to be ruled out on experimental grounds and we do not discuss it further.

The calculation of the electron-lattice coupling for 
$\mathrm{As}_{\mathrm{Ga}}$ in its ground $\mathrm{A}_{1}$ state has been performed [29]. It only considers a «breathing » mode, i.e. a displacement in which the four neighbours move radially by the same amont. They give numerical results for the corresponding force, showing that the amplitude of the relaxation is quite small (i.e. less than $0.5 \%$ of the bond length). From this result it is easy to determine the relaxation energies and to show that the Franck-Condon shift $d_{\mathrm{FC}}$ for the $\mathrm{As}_{\mathrm{Ga}}(0,+)$ transition must be smaller than 0.01 $\mathrm{eV}$. Since $d_{\mathrm{FC}}$ is found experimentally to be $\sim 130 \mathrm{meV}$ for EL2 electron ionization, one should again conclude that EL2 is not he isolated $\mathrm{As}_{\mathrm{Ga}}$ and that only a complex involving $\mathrm{As}_{\mathrm{Ga}}$ can be invoked.

In their search to demonstrate that a simple complex can explain the metastable behaviour of EL2, Baraff and Schlüter [30] considered the attractive case of $\mathrm{V}_{\mathrm{Ga}}$. They analysed the reaction $\mathrm{V}_{\mathrm{Ga}} \rightleftarrows \mathrm{V}_{\mathrm{As}}+\mathrm{As}_{\mathrm{Ga}}$ which only required hopping of the As atom. Although this simple complex does not meet the requirements of EPR and ENDOR spectra, the authors found that such a system could behave in a way similar to that of EL2. However, they concluded that it could not be identified with EL2 since its paramagnetic state definitely gives results in contradiction with those observed experimentally by EPR [2, 3].

Recently, the same authors have investigated the $\mathrm{As}_{\mathrm{Ga}}-\mathrm{As}_{\mathrm{i}}$ complex with interstitial arsenic in the $\mathrm{T}$ (2nd neighbour), $\mathrm{T}^{*}$ (1st neighbour) and $\mathrm{H}$ (intermediate) configurations [31]. They performed total energy calculations whose main results are : i) the close pair, $T^{*}$, is more stable than the $T$ one in $n$ type material and less stable in p-type material ; ii) the $T$ configuration is never stable compared to the isolated $A s_{\mathrm{Ga}}$ and $A s_{\mathrm{i}}\left(\mathrm{T}^{*}\right)$ pairs ; iii) the barrier $\mathrm{T}-\mathrm{H}-\mathrm{T}^{*}$ is of order $1.5 \mathrm{eV}$; iv) as for the $\mathrm{H}$ and $\mathrm{T}$ configurations, the defect separation is large enough for a simple point charge model to become meaningful which allowed them to develop detailed considerations based on an electrostatic model. For this, they adjusted the isolated $A s_{\mathrm{Ga}}$ levels on $E_{1}$ and $E_{2}$ and considered that the EPR active state was $\mathrm{As}_{\mathrm{Ga}}^{+}-\mathrm{As}_{\mathrm{i}}^{0}$. We have seen that these assumptions are not in agreement with recent experimental information so that some of their conclusions might be modified. It would be interesting to repeat their approach including these information and to continue the calculation to include the distortion of the $\mathrm{T}^{*}$ configuration, i.e. the split interstitial configuration [18], which is actually an As amorphous cluster.

\section{Discussion.}

We now consider the partial conclusions drawn in the previous sections and try to see if all fit within a unique reasonable picture.

We have seen that the $O$ state is a donor and should be identified to $\mathrm{O}^{2+}=\left(\mathrm{As}_{\mathrm{Ga}}^{+}-\mathrm{As}_{\mathrm{i}}^{+}\right)$in its EPR active state. The observed midgap level $E_{1}=E_{\mathrm{c}}-0.75 \mathrm{eV}$ must then correspond to the double donor state $(+, 2+)$ while the other state $E_{2}=E_{\mathrm{c}}-1 \mathrm{eV}$ should correspond to the $(2+, 3+)$ level. As no other deep level is observed for the $O$ configuration, one is then left with the conclusion that the single donor state $(0,+)$ has to be shallow and effective-mass like or within the condition band.

A question then arises concerning the possible configuration of the $\mathrm{O}^{+}$and $\mathrm{O}^{2+}$ states. We have precise information concerning the stable configuration since we have seen that the $\mathrm{O}^{+} / \mathrm{O}^{2+}$ transition, associated with the $E_{1}$ midgap level, corresponds to a Franck-Condon shift relatively weak of $\sim 0.14 \mathrm{eV}$ and a $20 \mathrm{meV}$ phonon energy, which is a normal average value if GaAs. This indicates that the $\mathrm{O}^{+}$state should be close to the orignal $\mathrm{O}^{2+}$ one with $\mathrm{As}_{\mathrm{i}}$ at the $\mathrm{T}$ site. In this distant pair the only possibility seems to be the electronic configuration $\left(\mathrm{As}_{\mathrm{Ga}}^{0}-\mathrm{As}_{\mathrm{i}}^{+}\right.$) since the other possibility $\left(\mathrm{As}_{\mathrm{Ga}}^{+}-\mathrm{As}_{\mathrm{i}}^{0}\right)$ would lead to a characteristic EPR spectrum. The $E_{1}$ level would then correspond to the $(0,+)$ level of the isolated $\mathrm{As}_{\mathrm{Ga}}$ lowered by $-\left(e^{2} / 2 \varepsilon R\right)$ due to the interaction with $\mathrm{As}_{\mathrm{i}}^{+}$at a distance of $2 R$. As $\left(e^{2} / 2 \varepsilon R\right) \sim 0.25 \mathrm{eV}$, this would place $\varepsilon(0,+)$ of the isolated $\mathrm{As}_{\mathrm{Ga}}$ at $0.5 \mathrm{eV}$ below the conduction band. This is in agreement with the EPR observations of reference [2] which put this level within the range 0.30 to $0.75 \mathrm{eV}$ from the conduction band.

We must now try to explain the transition to the metastable state. We view the $\mathrm{O}^{*}$ state as resulting from a displacement of $\mathrm{As}_{\mathrm{i}}$ to a closer distance (of the order of $R$ ) from $\mathrm{As}_{\mathrm{Ga}}$ followed by some eventual motion of the $A s_{\mathrm{Ga}}$ to minimize the elastic energy (it is proposed [18] that $\mathrm{As}_{\mathrm{i}}$ pushes the As atom of the antisite in such a way that the two As atoms are at equal distance from the original substitutional site, i.e. forming a so-called split interstitial configuration). This is a very important lattice relaxation which, in figure 2 , is denoted by the configuration coordinate $Q$. In this figure we have represented possible energy curves $E(Q)$ in the $\mathrm{O}$ and $\mathrm{O}^{*}$ states. We have neglected there the $0.14 \mathrm{eV}$ Franck-Condon shift of the $\mathrm{O}^{+} \rightarrow \mathrm{O}^{2+}$ transition. We have represented the $\sigma^{*}$ transition on the basis of the most simple parabola such that the vertical transition is at the observed energy : $h \nu_{0}=1.2 \mathrm{eV}$ and have taken total energies of $\left(\mathrm{O}^{*}\right)^{+}$and $\mathrm{O}^{+}$to be approximately the same. It is easy to see that $d_{\mathrm{FC}}$ for this transition is also of the order of $1.2 \mathrm{eV}$. The thermal barrier between the two configurations is $\left(h \nu_{0}\right)^{2} / 4 d_{\mathrm{FC}}$ which turns out to be 0.3 $\mathrm{eV}$, i.e. the activation energy of the thermal regeneration rate. Furthermore, an optical line shape theory 


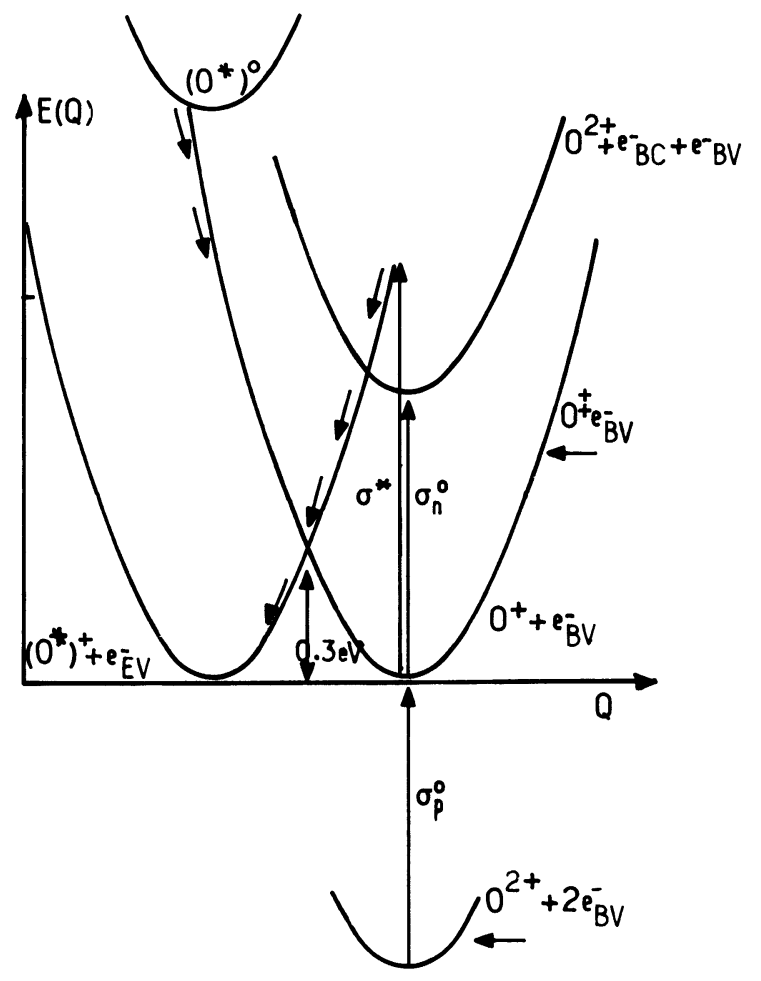

Fig. 2. - Configuration coordinate diagram for the stable (O) and metastable $\left(\mathrm{O}^{*}\right)$ states of EL2.

would predict for $\sigma^{*}(h \nu)$ a Gaussian curve of half-width $\Delta E=1.2 \sqrt{\hbar} \omega d_{\mathrm{FC}}$ which, taking $\hbar \omega \sim$ $10 \mathrm{meV}$ and $d_{\mathrm{FC}} \sim 1.2 \mathrm{eV}$ would give $\Delta E \sim 0.13 \mathrm{eV}$ of the order of the experimental value $(0.1 \mathrm{eV})$.

The same diagram allows also an interpretation of the regeneration rate under electron injection. Indeed the $\left(\mathrm{O}^{*}\right)^{+}$configuration is a donor system and can bind an extra-electron, at least in a shallow state, to give $\left(\mathrm{O}^{*}\right)^{0}$ as shown in the figure. In a regime of electron injection $\left(\mathrm{O}^{*}\right)^{+}$would transform to $\left(\mathrm{O}^{*}\right)^{0}$ which, according to figure 2 , could emit a hole to give $\mathrm{O}^{+}$with a very small activation energy.

Of course, the configuration coordinate diagram of figure 2 is over simplified. It contains crossing points where the energy curves should more or less repel ; however, this would not change the basic physical conclusions. It does not include explicitely the fact that the zero phonon line of the $\sigma^{*}$ transition is practically an $A_{1} \rightarrow T_{2}$ transition (but however it has not yet been clearly demonstrated that this zero phonon line participates directly in the quenching mechanism). One point which might be difficult to understand presently is the stability of the pair. From reference [31], only the $\mathrm{O}^{*}$ configuration in n-type material could be stable with respect to the separated pair $\mathrm{As}_{\mathrm{Ga}}$ and $\mathrm{As}_{\mathrm{i}}\left(\mathrm{T}^{*}\right)$ but, for positively charged states, $\mathrm{O}^{*}$ becomes unstable with respect to $\mathrm{O}$ (in view of Coulomb repulsion). This might explain why $\mathrm{O}^{2+}$ is favoured with respect to $\left(\mathrm{O}^{*}\right)^{2+}$ but one has still to explain why $\mathrm{O}^{2+}$ itself is stable. This might be related to the calculations concerning $A s_{i}$ which predict a $T_{2}$ state in the gap. Such a state leads to a Jahn-Teller distortion that can compete with Coulomb repulsion, as for vacancy centres in Silicon. This might be the origin of the fact that the $E_{1}$ level corresponds to the transition $\left(\mathrm{As}_{\mathrm{Ga}}^{+}-\mathrm{As}_{\mathrm{i}}^{+}\right) \rightarrow\left(\mathrm{As}_{\mathrm{Ga}}^{0}-\mathrm{As}_{\mathrm{i}}^{+}\right)$, i.e. no $\mathrm{As}_{\mathrm{i}}^{+} \rightarrow \mathrm{As}_{\mathrm{i}}^{0}$ transition is observed that, according to theoretical calculations, should be observed. Thus $\mathrm{As}_{i}^{+}$could be the only stable state of the interstitial at a $\mathrm{T}$ site, explaining why it is never observed. (A preliminary calculation [32] shows that this is likely to be the case).

\section{References}

[1] For a recent review see MARTIN, G. M. and MAKRAM-EBeId, S., In Deep Centers in Semiconductors, Ed S. T. Pantelides (Gordon \& Breach, New York). 6 (1986).

[2] Von Bardeleben, H. J., Stievenard, D., Bourgoin, J. C. and Huber, A., Appl. Phys. Let. 47 (1985) 970.

[3] Von Bardeleben, H. J., Stievenard, D., DereSME, D., Huber, A. and Bourgoin, J. C., Phys. Rev. B. 34 (1986) 7192.

[4] Mircea, A., Mitonneau, A., Hollan, L. and Brière, A., Appl. Phys. 11 (1976) 153.

[5] There is a considerable scatter on the values of this energy level reported in the literature. The reason is that the apparent ionization energy, as deduced from DLTS depends strongly on experimental conditions such as electric field, leakage current, ratio of the defect to the free carrier concentrations. The value given here is the one proposed in reference [1], which takes into account these effects as well as the temperature dependence of the carrier capture cross-section and the entropy term.

[6] Osaka, J., OKamoto, H. and Koyayashi, K., in Semi-Insulating III-V Materials (Ohmsha) (1986) 421.

[7] Vincent, G., Bois, D. and Chantre, A., J. Appl. Phys. 53 (1982) 3643.

[8] Makram-Ebeid, S. and Lannoo, M., Phys. Rev. B 25 (1982) 6406.

[9] Chantre, A., Vincent, G. and Bois, D., Phys. Rev. B 23 (1981) 5335.

[10] Mircea-Roussel, A. and MaKram-Ebeid, S., Appl. Phys. Lett. 38 (1981) 1007.

[11] Leyral, P., Vincent, G., Nouilhat, A. and GuilLOT, G., Solid State Commun. 42 (1982) 67.

[12] Mitonneau, A. and Mircea, A., Solid State Commun. 30 (1979) 157. 
[13] KaminsKa, M., Skowronski, M., LAGowsKi, J., Parsey, J. M. and Gatos, H. C., Appl. Phys. Lett. 43 (1983) 302.

[14] Manasreh, M. O. and Covington, B. C., Phys. Rev. B 35 (1987) 2524.

[15] Weber, E. R., EnNen, H., Kaufman, U., WINDSCHEIF, J., SCHNEIDER, J. and WoSINSKI, T., J. Appl. Phys. 53 (1982) 6140.

[16] Meyer, B. K., HofmanN, D. M. and Spaeth, J.M., In Defects in Semiconductors, Ed H. J. von Bardeleben (Trans. Tech. Publ.). Mater. Sci. Forum 10-12 (1986) 311.

[17] Levinson, M., Phys. Rev. B 28 (1983) 3660.

[18] Von BARdeleben, H. J., Bourgoin, J. C., Stievenard, D., LANNOO, M., Proc. 14th Int. Symp. on GaAs and related Compounds (Herakhon, Creete, 1987) to be published.

[19] Wager, J. F. and Van Vechten, J. A., Phys. Rev. B 35 (1987) 2330.

[20] Zou Yumxi, Inst. Phys. Conf. Ser. 63 (1982) 185.

[21] Dannefaer, S. and Kerr, O., J. Appl. Phys. 60 (1986) 591.

[22] FIGIELSKI, T., in Defects in Semiconductors, Ed H. J. von Bardeleben (Trans. Tech. Publ.), Mater. Sci. Forum 10-12 (1986) 341.
[23] Mochizuki, Y. and Ikoma, T., in Defects in Semiconductors, Ed H. J. von Bardeleben (Trans. Tech. Publ.), Mater. Sci. Forum 10-12 (1986) 323.

[24] Lannoo, M., in Current issues in Semiconductor 'Physics, Ed M. Stoneham (Adam Hilger, Bristol) 2 (1986).

[25] Mauger, A., Von Bardeleben, H. J., Bourgoin, J. C. and Lannoo, M., Phys. Rev. B 36 (1987) 5982.

[26] Baraff, G. A. and Schluter, M., Phys. Rev. B 19 (1979) 4965.

[27] Bernholz, J., Lipari, M. O. and Pantelides, S. T., Phys. Rev. B 21 (1980) 3545.

[28] BarafF, G. A., Schlüter, M. and Bachelet, G. B., Phys. Rev. B 27 (1983) 2545.

[29] BaChelet, G. B. and SCHEFfler, M. in Int. Conf. on the Physics of Semiconductors, Eds J. D. Chadi and W. A. Harrison (Springer Verlag, Berlin) 1985, p. 755.

[30] Baraff, G. A. and Schlüter, M., Phys. Rev. B 35 (1987) 5929.

[31] Baraff, G. A. and Schlüter, Phys. Rev. B 35 (1987) 6154.

[32] LANNOO, M., unpublished. 